\title{
A Tentative Discussion on Analysis Methods of Bel Canto
}

\author{
Na Lu \\ Faculty of Humanity, Jiangxi University of Traditional Chinese Medicine, Nanchang, 330004, China
}

Keywords: Bel canto, Skills, Emotional processing.

\begin{abstract}
As a very important part in the development of music, bel canto plays a very important role in the field of vocal music. Therefore, based on this, it is very important to have the further discussion on the strengthen of tackling some aspects like singing skills and emotional expression. This not only helps the speaker to constantly improve his or her singing level during the performance of bel canto, but also comprehensively analyzes his or her singing defects, and solves problems such as improper application of skills through analysis, so as to achieve the effect of improving his or her singing level. This paper starts with the singing skills of bel canto, and elaborates the specific treatment of emotion during the performance of bel canto, so as to achieve the perfect state of the interpretation of the works and meet the audience's demand for music.
\end{abstract}

\section{Introduction}

Bel canto was invented by the Italians and was introduced to China in the 1930s. To a certain extent, the application of bel canto enriches the national singing forms of music, and plays a very important role in promoting Chinese national singing forms' integrating into Italian language for the creation of works. In the process of guiding the singer to perform, the singer's emotional expression can be constantly improved, and the audience can be guided to achieve emotional resonance. So, the expression of bel canto and the content of art show have a high level of appreciation. This paper takes singing skills of bel canto as the entry point, and expatiates the specific way of emotional processing in detail, in order to provide text reference for program innovation and development in vocal music field, as well as the solutions to problems encountered by singers in the process of singing, constantly improving the performance level of singers.

\section{The analysis on singing skills in bel canto}

\subsection{The analysis on breathing skills while singing}

As far as the performance of the song is concerned, the singer needs to control his breathing constantly to ensure the integrity of the song performance. Bel canto, as the most rigorous form of singing, requires more on breathing. Therefore, if singers need to take the breathing training, the integrated of mouth, nose and chest breathing training should be carried out. The breathing training can help the singer to relax the body to the maximum extent and achieve the flexible application of breath. In the process of practical training, the chest and shoulders must be in a relaxed state, and the breath-taking can be achieved by the careful breathing, so that they can ensure the incoming breath can reach the deepest part of the spirit, which is also a very important part to ensure the breath-taking. In addition, the inhaled breath, to a certain extent, will cause the expansion of the rib, which makes the diaphragm appear too nervous phenomenon. Therefore in design of breathing training, the training of diaphragmatic breathing mode should be strengthened, so as to improve the overall level of breathing.

To ensure the stability of the breathing is the important premise of the completeness of the song during the performance. Therefore, singers must be in a relax breathing-take state during the performance. So, for the training of breathing methods, it is important to do the comprehensive training like chest breathing, abdominal breathing, thoracoabdominal breathing, and to pay attention 
to the collaborative application of various training methods. For example, the in-time adjustment must be taken and the flexible change to various breathing ways must have during the chest breathing. Ensure the upper chest and shoulder lifting movements, which will play an auxiliary role in regulating the breathing mode to a certain extent. Breath is a very basic condition in bel canto. If there is no breath to support, then there is no beauty in music, and the stable breath is a necessary way to present beauty in music. Due to its different sound positions when singing, the expression of emotion of the song will be blocked if the high and low voices are not supported by the necessary breath. The expression of emotion refers to the continuous exchange of breath by taking the diaphragm muscle as the fulcrum to breathe. This chest movements rely mainly on the contraction of diaphragm muscle to complete, which also is called as " sink your breath to the dan tian (lower belly)". Using the contraction of the diaphragm can do music of partitions, and implement the flexible change of bel canto in high and low, so the necessary breath training can improve the level of the singer's performance.

\subsection{The analysis on resonance skills during singing}

Resonance is a very important part of vocal performance. It requires a lot to the singer's comprehensive quality, and it is an important part in the vocal performance as well. The application of the head cavity resonance technique is very important in the whole singing process. The head cavity resonance can ensure the head vibration to a certain extent and achieve the corresponding nasal resonance effect.

When singing bel canto, the head cavity resonance must be strengthened during the expression of the high tone. In order to improve the sound recognition degree, it is necessary to identify the differences between the sound areas, so as to improve the recognition degree, and finally achieve the higher coordination, then the song can be completed. In addition, oral resonance is also a very important expression form of music. In the process of singing, bel canto requires the singer to ensure the coordinated application of laryngeal cavity, oropharyngeal cavity and nasal cavity, and make proper opening and closing, so as to realize the resonance of cavity.

Chest resonance, as the lowest part of the body, has a very important application in the bel canto bass region. In the process of bass performance, the chest resonance is required to achieve the limited play of resonance effect. In addition, the resonance applications to a singer, is the very important bel canto singing skills. The flexible application and collaborative cooperation of it are the key to achieve the complete expression of songs. At the time of ensuring the integrity of performance organs, the collaborative cooperation between the resonance organs and other organs are also needed to be ensured, so that the singer's singing skills can be enhanced. Moreover, it can weaken the strident tone to a certain extent and provide some cover for the whole singing. Cavity resonance is the main method to modify music, which is equivalent to the reverberation in the sound system. The sound generated by our own band is somewhat thin and has no artistic modification. In the process of singing, the sound of the artist is modified, which makes it more vivid and beautiful and has strong penetration and influence. And this is the scientific modification of the sound through resonance by the performer. However, oral resonance and chest resonance usually require constant and flexible conversion. The more the vocal regions are differentiated, the more frequently the resonance is used. In order to achieve the synergistic effect of these three kinds of resonance in the process of singing, according to the structure of the human body, the maximum sound emitted from space when chest resonance is low, which is the key to bass resonance. Therefore, reasonable resonance training and transformation of resonance skills can provide listeners with a richer listening experience.

\subsection{The analysis on throat opening during singing}

As the place of vocal cords, the sound produced by the throat plays a decisive role in the quality of singing. Therefore, the degree and way of throat opening are very important parts in singing bel canto. The oral cavity resonance is the most widely used in bel canto, and it can directly affect the presentation of singer's singing level and perfect singing skills. However, in the actual process of singing, the open way of throat has more complex features, so throat open should be the training focus 
when the singer opens the throat. From the simple opening of the throat, it extends to the part of the throat, larynx and other fields, so as to ensure that the throat has accurate characteristics in the way of opening, and can meet the requirements for skills of singing in bel canto. As a great deal of experimental researches shown that yawning can be an important way to train the throat cavity open. The throat can be fully opened through yawning, so that the singer can be in a relax state and show the "smiling" attitude to the audience during the performance. Then, the open degree of throat can meet the requirements of singer's singing skills, and the mouth will be opened through smiling as well, which can realize the nasal cavity and pharynx opening in the maximum extent. In addition, the emotion of the singer can be aroused to a certain extent, so as to better participate in the singing performance, and express the work's emotions most accurately in the process of enjoying the stage.

Correct pronunciation method is an essential quality for an excellent singer. As long as the song is accurately expressed in the process of singing, then it is very important to learn the mixing of true and false sound. Everyone's true voice has the height limits. Normally, the voice height of girl is higher than the boy's. If the change of true and false voice is not taken but to use the true voice all the time, then it will have a deep impact to the vocal cords. The best way to protect the vocal cords is to open and close the throat properly.

\section{Specific measures of emotional treatment of songs by bel canto singers}

In order to be an excellent singer, it is not only to master the necessary bel canto skills, but also to deal with the emotions of the works. Only by touching the audience with emotion can the audience be more aroused, which will truly realize the integration of people and songs.

In the actual singing process, if the singer wants to truly understand the work and conduct proper emotional processing, then he or she should have a detailed understanding of the composer's creation background and the author's own life experience. The singer should be able to consider the author's intention of writing the song at that time, and then makes artistic processing when accurately grasping the emotional tone of the song. There are two kinds ways to master the emotional keynotes. One is the emotional keynotes, single-mindedness, happy, sad or angry. The other is the change of emotion in the song, maybe it is from happy to sad, and then happy. Or it is from sad or alone to angry, etc. All the emotional keynotes require the singer to express the emotions with empathy. Meanwhile, the singer should also pay attention to the control of the singing rhythm. On the one hand, the singing speed and strength should be ensured. On the other hand, the singer should so some appropriate artistic modifications on the song according to his or her own understandings. Finally, it is important to understand the meaning of lyrics. The reason why the song can be a unique art is the expression of lyrics, which is to modify the language in an artistic way and then to present it to the audience in the singing form. Therefore, before singing, the singer needs to have the detailed analysis on understanding the lyrics, and thinks about what the author thought and what kind of emotion the author wanted to express by using the lyrics when creating the work. And all these have great help to the singer.

For example, the famous song "My sun" in bel canto is written by the Italian writer Di Capua. Di Capua waked up in a hotel one day when followed his father during a performance tour, and he found the sun rise. All peace was broken by a ray of sunshine. Therefore, he wrote this down and created this classic work. And this is the background of the song. As for the thoughts of Di Capua at that time, different people have different opinions. Therefore, it has a lot spaces for singers to perform. Some people hold that the sun in the song is love, but some think lover, kinship, or the profound friendship between brothers. As the famous writer once said, there are a thousand hamlets in a thousand hearts. So every singer, according to their own experience and the detailed analysis of its author's life experience, has their own unique perspective. And they all have their own emotional processing on the expression of song, and perform the song with unique emotions. They convey the different emotions to the audience, which all require the detailed thinking of singers.

By exploring the author's intention at that time through detailed discussion, the song can be guaranteed to capture the audience's attention and generate emotional resonance with the audience. 


\section{Summary}

The cultivation of bel canto is a very complicated and long process. Besides mastering the basic theoretical knowledge, it is necessary to carry out continuous practice. In the process of practice, we should pay attention to summarizing, experiencing and understanding. Only by find feelings can singers improve their singing skills of bel canto.

\section{Acknowledgement}

This work was supported by the 2016 Jiangxi University of Traditional Chinese Medicine School-level Teaching Reform Project: One of the research results of "The Practice and Reform of Music Therapy in Traditional Vocal Teaching”, No.: 2151701413.

\section{References}

[1] Gong Ran; Skills and improvement in the use of breath in bel canto, Shenzhou (next ten days publication); 2018, 4, P18.

[2] Yang Dazhen; The discussion on the combination of emotion and skill in bel canto, Appreciation of art; 20, p139-140 in 2018.

[3] Song Xue; Exploring a new way of singing Chinese bel canto: Peng Kangliang: applying the beauty of Chinese to bel canto, Army people music. 2015, 5, p4-7.

[4] Gao Bo; The influence of the application of skills and breath in bel canto on emotional expression, Popular literature and art; 2017,13, P156.

[5] Gao Yangyang; Analysis on the fusion of bel canto singing skills and styles in vocal music teaching and Chinese native vocal music art, The house of drama; 2018, 16, P183.

[6] Fan Huimin; The importance of "qi" and "dian" in the training of bel canto, Zhiyin inspiration; 2017, 8, P222.

[7] Zhan Shubo; Application of traditional Chinese treble singing method in the teaching of bel canto, Popular songs; 2017,1, P96. 